\title{
The Utilization of Physisorption Analyzer for Studying the Hygroscopic Properties of Atmospheric Relevant Particles
}

\author{
Qingxin Ma, Yongchun Liu, and Hong He* \\ State Key Laboratory of Environmental Chemistry and Ecotoxicology, Research Center for Eco-Environmental \\ Sciences, Chinese Academy of Sciences, 18 Shuangqing Road, Haidian District, Beijing 100085, China
}

Received: September 29, 2009; Revised Manuscript Received: February 1, 2010

\begin{abstract}
The hygroscopic behavior of atmospheric aerosols has a significant effect on the global climate change. In this study, a physisorption analyzer was used to measure the water adsorption capacity of $\mathrm{Al}_{2} \mathrm{O}_{3}, \mathrm{NaCl}_{2} \mathrm{NH}_{4} \mathrm{NO}_{3}$, and $\left(\mathrm{NH}_{4}\right)_{2} \mathrm{SO}_{4}$ particles at $273.6 \mathrm{~K}$. Qualitative and quantitative information about water adsorption on these particles was obtained with changing the temperature and/or relative humidity (RH). Uptake of water on $\mathrm{Al}_{2} \mathrm{O}_{3}$ showed a type-II BET adsorption isotherm with the monolayer formed at $\sim 18 \%$ relative humidity (RH). The hygroscopic properties of $\mathrm{NaCl},\left(\mathrm{NH}_{4}\right)_{2} \mathrm{SO}_{4}$, and $\mathrm{NH}_{4} \mathrm{NO}_{3}$, including the deliquescence relative humidities (DRH), the temperature dependence of the $\mathrm{DRH}$ for $\mathrm{NH}_{4} \mathrm{NO}_{3}$, and the growth factors of $\mathrm{NaCl}$ and $\left(\mathrm{NH}_{4}\right)_{2} \mathrm{SO}_{4}$ were determined. All these results were in good agreement with the results obtained by other methods and/or theoretical prediction with a deviation less than $2 \%$. For $\mathrm{NaCl}$, the water adsorption amount increase rate exhibits three stages $(<30 \% \mathrm{RH}, \sim 30 \%-65 \% \mathrm{RH}$, and $>65 \% \mathrm{RH})$ in the predeliquescence process and monolayer thin film water was formed at about $30 \% \mathrm{RH}$. It demonstrated that this instrument was practicable for studying the hygroscopic behavior of both soluble and insoluble but wettable atmospheric nonviolate aerosol particles.
\end{abstract}

\section{Introduction}

Technically, an aerosol is a suspension of fine solid particles or liquid droplets in gas, ${ }^{1}$ with the major components being mineral dust, sea salt, and secondary aerosols. ${ }^{2}$ In recent years, the study of aerosol particles and their impact on the environment and climate has intensified. While the combined positive climate forcing of the greenhouse gases can be fairly well estimated, the complexity of the aerosol-cloud-climate system makes the negative forcing due to atmospheric aerosols the largest current source of uncertainty in predictions of the future global climate. ${ }^{3}$ Atmospheric aerosols affect climate directly through scattering, transmission, and absorption of solar radiation, and indirectly through changing the optical properties and lifetime of clouds by acting as cloud condensation nucleus (CCN). ${ }^{4}$ The physicochemical properties of aerosol are strongly dependent on their phase, namely, water content, which varies with different relative humidities (RH). In general, solid salt particles which are hygroscopic in nature take up water in the atmosphere and form aqueous droplets. The hygroscopic growth influences light scattering, cloud formation and precipitation, the atmospheric lifetime, and the chemical reactivity of the individual particles. ${ }^{5-7}$ The hygroscopic properties of the aerosol also determine which fraction of aerosol particles can act as $\mathrm{CCN}$ and thus contribute to the aerosol indirect effect. ${ }^{8}$ For mineral dust particles, the water content has a significant influence on its physiochemical and photochemical properties. ${ }^{9}$ Due to its great importance, the hygroscopic behavior of aerosol particles has been a major focus of atmospheric science. Therefore, it is very significant to develop reliable measurement methods or apparatus for hygroscopicity studies.

There are a variety of techniques applied to obtain the information on the hygroscopic behavior of particles, including

* Corresponding author: telephone, +86-10-62849123; fax, +86-1062923563; e-mail, honghe@rcees.ac.cn. nephelometry, ${ }^{10}$ tandem differential mobility analysis ( $\mathrm{T}$ DMA), ${ }^{8,11-15}$ electrodynamic balance (EDB), ${ }^{16-18}$ infrared spectroscopy (IR), ${ }^{19-22}$ Raman spectroscopy, ${ }^{23,24}$ and microscopic methods. ${ }^{25-28}$ As a well-established aerosolized technique, T-DMA has been used in field campaigns in various environments globally over the last 2 decades to determine the water uptake on submicrometer particles at subsaturated conditions. These investigations have yielded valuable and comprehensive information regarding the particle hygroscopic properties which determine the equilibrium particle size at ambient relative humidities, as summarized in a recent review. ${ }^{29}$ EDB was another method which kept a single, charged particle as aerosolized state by applying a balance between electronic field and gravity field. This technique allowed the thermodynamics of highly supersaturated solutions to be studied and the water activity as a function of concentration for aqueous solutions to be measured. ${ }^{17}$ Infrared spectroscopy, including transmission FTIR, ${ }^{22,30}$ aerosol flow tube (AFT-FTIR), ${ }^{19}$ attenuated total reflection (ATR-FTIR), ${ }^{20}$ and diffuse reflection infrared Fourier transform spectroscopy (DRIFTS), ${ }^{21}$ are useful for determining the structure of molecules adsorbed on aerosol particle surfaces since this technique is sensitive to the phase of water, i.e., gas, liquid, or solid. It could provide insight into the nature of the surface hydrogen bonding networks as well as the phase change of aerosol particles. Raman spectroscopy, which is very sensitive to the phase states (dissolved or solid) and the molecular interactions of solute, is a common single particle spectroscopic technique for studying morphological resonance structure in the inelastic scattering of droplets. Moreover, environmental scanning electron microscopy $(\mathrm{ESEM})^{25}$ and environmental transmission electron microscopy $(\text { ETEM })^{28}$ enable an in situ observation of the interaction between liquid water and aerosol particles with diameters in the submicrometer range. Drop formation and particle growth, water adsorption, and activation of aerosol particles can be imaged. In addition, the chemical 


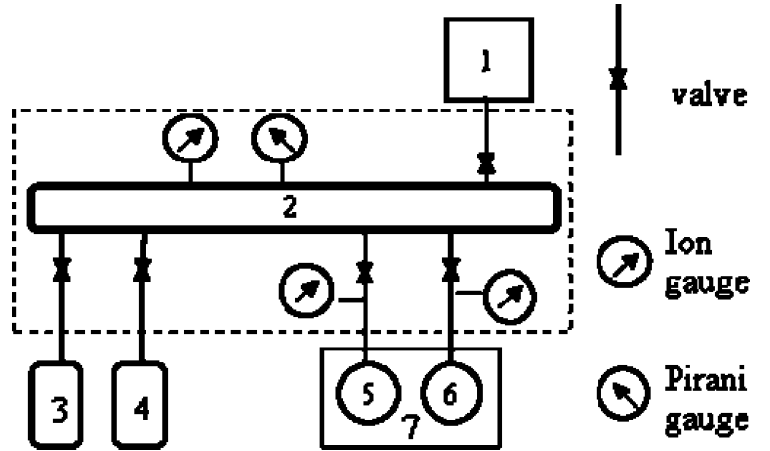

Figure 1. Schematic of AUTOSORB-1-C for water adsorption: (1) turbo pump; (2) manifold tube; (3) He cylinder; (4) adsorbate (water with super purity); (5) sample station; (6) $P_{0}$ station; (7) ethanol-cycle bath. The dash pane represents a warm cloth for the manifold.

composition of individual particles can be studied in the same instrument by energy-dispersive X-ray microanalysis. ${ }^{26}$ Atomic force microscopy (AFM) ${ }^{27}$ is also applied to study the morphology of wet and dry individual particles, as well as the adsorption active sites for water adsorption. In this paper, a new method using a modified physisorption analyzer was applied to investigate the water adsorption capacity of soluble and insoluble particles by accurately measuring their water adsorption isotherms and hygroscopic behavior.

The physisorption analyzer with nitrogen as adsorbate was well established for determining the specific surface area and pore size distribution of materials. ${ }^{31}$ When water vapor was used as adsorbate, it can provide qualitative and quantitative information about the hygroscopicity of aerosol particles by making direct measurement of the adsorption of water on a solid surface. Therefore, we utilized a modified nitrogen autosorb analyzer to study the hygroscopic properties of aerosol particles. $\mathrm{Al}_{2} \mathrm{O}_{3}$, $\mathrm{NaCl},\left(\mathrm{NH}_{4}\right)_{2} \mathrm{SO}_{4}$, and $\mathrm{NH}_{4} \mathrm{NO}_{3}$ were chosen for the representation for mineral dust, sea salt, and secondary fine aerosols. ${ }^{2,32,33}$ Adsorptions of water on these atmospheric particles at $273.6 \mathrm{~K}$ were investigated. Our purpose was to demonstrate that the water adsorption capacity of aerosol particles can be determined quantitatively by a vapor adsorption analyzer, which is also a convenient and inexpensive method.

\section{Experimental Section}

All measurements were carried out in an AUTOSORB-1-C (Quantachrome, US) instrument equipped with a vapor generator. Figure 1 shows the schematic diagram of the experimental setup. The system includes a manifold tube (steel, $V=18.6632$ $\left.\mathrm{cm}^{3}\right)$, which is kept in a constant temperature $(323 \pm 0.5 \mathrm{~K})$ chamber to avoid vapor condensation during the vapor adsorption experiments. The insulated chamber contains a manifold heater and circulation fan inside. The manifold tube is connected to turbo pump, helium port, vapor generator, $P_{0}$ station, and sample station. The vapor generator consists of a glass bulb in which liquid water (vapor source) is held. A station is a port which is isolated from the manifold tube with a solenoid valve. A glass tube is attached to the station by an O-ring seal during the experiments. The $P_{0}$ station is the reference tube which is used to automatically measure the $P_{0}$ value at a given temperature (77 $\mathrm{K}$ for nitrogen adsorption). For water adsorption experiments, the temperatures of the $P_{0}$ station and sample station were controlled by using an ethanol-cycle bath, whose temperature can be controlled from 220 to $373 \mathrm{~K}$ within \pm 0.10 $\mathrm{K}$ by using a superthermostat and a cryofluid pump (DFY 5/80, Henan Yuhua laboratory instrument factory).
In a typical experiment, the volumes of manifold and sample tube are measured with helium before the adsorption process. The pressure change during the adsorption-desorption process, which is used to calculate the gas lost due to adsorption, is monitored by manometers for manifold tube, $P_{0}$ station, and sample station, respectively. As recommended by the manufacturer, when the pressure change during adsorption process is less than $0.2 \%$ within 2 min (for $\mathrm{N}_{2}$ adsorption, it is $0.01 \%$ ), it is considered to be equilibrated. If the pressure change is larger than $0.2 \%$, the same process was repeated until it is less than $0.2 \%$. The whole process is program-controlled. At first, a reference experiment with the $P_{0}$ tube and empty sample tube was conducted. The result showed that the adsorption amount of water on tube wall was negligible compared to that on samples. The $P_{0}$ value established in the reference experiment was recorded $\left(P_{0}=4.85 \mathrm{mmHg}, T=273.6 \mathrm{~K}\right)$. In the experiments of vapor adsorption on samples, the $P_{0}$ value is no longer measured and directly input as $4.85 \mathrm{mmHg}$ gained from the reference experiment. When the experimental temperature was changed, the same processes were conducted.

Sources of Chemicals. Sodium chloride (AR, >99.5\% Sinopharm Chemical Reagent Co. Ltd.), ammonium sulfate (AR, $>99 \%$ Beijing Chemical Reagent), and ammonium nitrate (AR, $>99 \%$ Guangdong Xilong Chemical Company) were used as purchased. The Brunauer-Emmett-Teller (BET) analysis ${ }^{31}$ was performed in this instrument when nitrogen $\left(\mathrm{N}_{2}\right)$ was used as adsorbate and the $P_{0}$ and sample stations were placed in liquid nitrogen. The BET surface areas were $0.22,0.15$, and $0.16 \mathrm{~m}^{2} / \mathrm{g}$ for $\mathrm{NaCl},\left(\mathrm{NH}_{4}\right)_{2} \mathrm{SO}_{4}$, and $\mathrm{NH}_{4} \mathrm{NO}_{3}$, respectively. The $\mathrm{Al}_{2} \mathrm{O}_{3}$ sample was prepared from boehmite $(\mathrm{AlOOH}$, supplied by Shangdong Alumina Corporation) by calcining at $1473 \mathrm{~K}$. It was identified as $\alpha-\mathrm{Al}_{2} \mathrm{O}_{3}$ by $\mathrm{X}$-ray diffraction analysis ( $\mathrm{X}^{\prime}$ Pert PRO-PANalytical, Netherlands) with the three main peaks at $35.0^{\circ}, 43.0^{\circ}$, and $57.0^{\circ}$ (ICDD 81-2267). The alumina samples were heated at $573 \mathrm{~K}$ in a vacuum system for $3 \mathrm{~h}$ to remove surface-adsorbed species before adsorption measurement. Superpure water (18 M $\Omega$ ) was used in all water uptake experiments. The particle sizes measured by scanning electron microscopy (SEM-HITACHI, Japan) is in the range $0.1-5 \mu \mathrm{m}$ with a mean diameter of $1 \mu \mathrm{m}$ for $\alpha-\mathrm{Al}_{2} \mathrm{O}_{3}, 1-30 \mu \mathrm{m}$ with the mean diameter of $10 \mu \mathrm{m}$ for $\mathrm{NaCl}$ and $\left(\mathrm{NH}_{4}\right)_{2} \mathrm{SO}_{4}$, and $1-50$ $\mu \mathrm{m}$ with the mean diameter of $30 \mu \mathrm{m}$ for $\mathrm{NH}_{4} \mathrm{NO}_{3}$, respectively.

\section{Results and Discussion}

Nitrogen and Water Adsorption Isotherms on $\alpha-\mathrm{Al}_{2} \mathrm{O}_{3}$. We first studied nitrogen adsorption at $77 \mathrm{~K}$ as well as water adsorption at $273.6 \mathrm{~K}$ on $\alpha-\mathrm{Al}_{2} \mathrm{O}_{3}$ to test the feasibility of this system. $\mathrm{SiO}_{2}$ and $\alpha-\mathrm{Al}_{2} \mathrm{O}_{3}$ are two major components of mineral dust from Sahara ${ }^{32}$ and Asia. ${ }^{33}$ In contrast to the inertness of $\mathrm{SiO}_{2}$ to most reactive pollutants, $\mathrm{Al}_{2} \mathrm{O}_{3}$ is very reactive to many atmospheric trace pollutants. Therefore the study of water adsorption on $\alpha-\mathrm{Al}_{2} \mathrm{O}_{3}$ is also significant for atmospheric science. The results of nitrogen and water adsorption on $\alpha-\mathrm{Al}_{2} \mathrm{O}_{3}$ are shown in Figure 2. For nitrogen adsorption, the BrunauerEmmett-Teller (BET) $)^{34,35}$ method is the most widely used procedure for the determination of the surface area of solid materials and involves the use of the BET equation

$$
\frac{1}{V\left(\frac{P_{0}}{P}-1\right)}=\frac{1}{V_{\mathrm{m}} C}+\frac{C-1}{V_{\mathrm{m}} C} \frac{P}{P_{0}}
$$

where $V$ is the volume of gas adsorbed at a relative pressure $\left(P / P_{0}\right)$ and $V_{\mathrm{m}}$ is the volume of adsorbate constituting a 

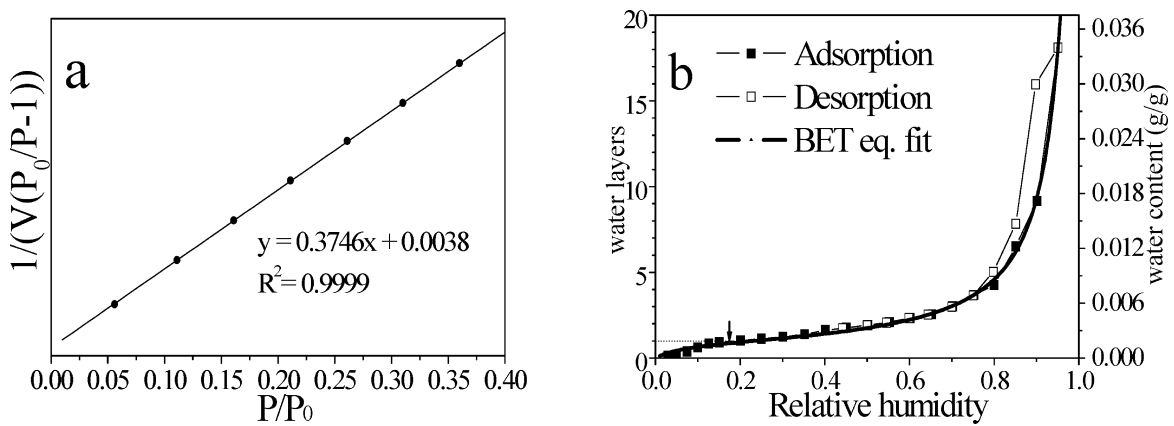

Figure 2. Adsorption isotherm about $\alpha-\mathrm{Al}_{2} \mathrm{O}_{3}$ of (a) nitrogen at $77 \mathrm{~K}$ and (b) water at $273.6 \mathrm{~K}$. Solid square, open square, and dash line represent adsorption, desorption, and three-parameter BET equation fit isotherm, respectively. $m_{\text {sample }}=120.5 \mathrm{mg}$.

monolayer of surface coverage. The BET $C$ constant is related to the energy of adsorption in the first adsorbed layer, and consequently its value is an indication of the magnitude of the adsorbent/adsorbate interactions. It is determined as

$$
C=\exp \left[-\frac{\Delta H_{1}{ }^{0}-\Delta H_{2}{ }^{0}}{R T}\right]
$$

where $\Delta H_{1}{ }^{0}$ is the standard enthalpy of adsorption of the first layer, $\Delta \mathrm{H}_{2}{ }^{0}$ is the standard enthalpy of adsorption on subsequent layers and is taken as the standard enthalpy of condensation, $R$ is the gas constant, and $T$ is the temperature in kelvin.

For most solids, using nitrogen as the adsorbate, a linear plot of $1 /\left[V\left(P_{0} / P-1\right)\right]$ vs $P / P_{0}$ derived from eq 1 is restricted to a limited region of the adsorption isotherm, usually in the $P / P_{0}$ range of $0.05-0.35 .{ }^{31}$ The linear plot in this range is shown in Figure $2 \mathrm{a}$. The result showed a good linear relationship with a correlation coefficient 0.9999 . The volume of a monolayer of adsorbate $V_{\mathrm{m}}$ can then be obtained from the slope $s$ and intercept $i$ of the BET plot by the calculation from eq 3

$$
V_{\mathrm{m}}=\frac{1}{s+i}
$$

With the assumption of the cross-sectional area for nitrogen at $77 \mathrm{~K}$ to be $16.2 \AA^{2},{ }^{36}$ the specific surface area of $\alpha-\mathrm{Al}_{2} \mathrm{O}_{3}$ was calculated to be $11.5 \mathrm{~m}^{2} / \mathrm{g}$.

For water adsorption, as seen in Figure 2b, hysteresis was observed between adsorption and desorption at high $\mathrm{RH}$. The adsorption isotherm exhibits a type-II characteristic, ${ }^{31}$ and it was not well fitted with eq 1 (correlation coefficient $=0.9$ ). The three-parameter BET equation assumes that the number of layers of gas adsorbing at high values of $P / P_{0}$ is not infinite but a limited value $n$. The three-parameter BET equation is then ${ }^{37}$

$$
V=\left[\frac{V_{\mathrm{m}} C \frac{P}{P_{0}}}{1-\frac{P}{P_{0}}}\right]\left[\frac{1-(n+1)\left(\frac{P}{P_{0}}\right)^{n}+n\left(\frac{P}{P_{0}}\right)^{n+1}}{1+(C+1) \frac{P}{P_{0}}-C\left(\frac{P}{P_{0}}\right)^{n+1}}\right]
$$

where $P, P_{0}, V, V_{\mathrm{m}}$, and $C$ are defined as they were in eq 1 and $n$ is an adjustable parameter given as the maximum number of layers of the adsorbing gas and is related to the pore size and properties of adsorbent.

The water adsorption isotherm was fitted with the threeparameter BET equation with a correlation coefficient 0.9991 . The result gave other parameters as $V_{\mathrm{m}}=2.334 \mathrm{~cm}^{3}(\sim 18 \%$

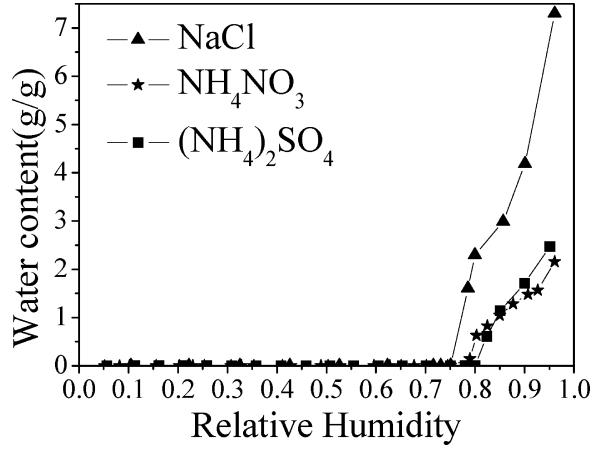

Figure 3. Adsorption isotherms of water on $\mathrm{NaCl}$ (solid triangle), $\mathrm{NH}_{4} \mathrm{NO}_{3}$ (solid star), and $\left(\mathrm{NH}_{4}\right)_{2} \mathrm{SO}_{4}$ (solid square) at $273.6 \mathrm{~K}$. The sample masses were $7.2,9.1$, and $7.7 \mathrm{mg}$, respectively.

RH), $C=15$ and $n=91$, respectively. With the assumption of the cross-sectional area for water at $273 \mathrm{~K}$ to be $14.3 \AA^{2},{ }^{21}$ the specific surface area of $\alpha-\mathrm{Al}_{2} \mathrm{O}_{3}$ was calculated to be $9.7 \mathrm{~m}^{2} / \mathrm{g}$. The discrepancy between these two measured surface areas may be due to the different properties of two adsorbates. ${ }^{38}$ The monolayer formed at $\sim 18 \% \mathrm{RH}$ was in good agreement with the result of a spectroscopic study at $298 \mathrm{~K}(\sim 17 \% \mathrm{RH})$ by Goodman et al. when transmission FTIR was used. ${ }^{30}$ The smaller value of $C(=15)$ in this work compared to Goodman et al., ${ }^{30}$ who gave a value $C=25$, may be due to the low experiment temperature. However, there exists a big discrepancy for $n$ between our result about 91 and 8 of Goodman et al. ${ }^{30}$ The reason was that infrared spectroscopic method makes an underestimation of the surface adsorbed water amount at high $\mathrm{RH}$, which has also been demonstrated by comparison with a thermogravimetric analysis. ${ }^{21}$ The relatively high value of $n=$ 91 also indicates that capillary phenomena may exist. It suggested that this system is practicable for the study of water adsorption on atmospheric relevant particles.

Deliquescence Points Measurements. The isotherms of water adsorption on $\mathrm{NaCl}, \mathrm{NH}_{4} \mathrm{NO}_{3}$, and $\left(\mathrm{NH}_{4}\right)_{2} \mathrm{SO}_{4}$ at 273.6 $\mathrm{K}$ are shown in Figure 3. It shows that, at low relative humidities, there are only a few thin layers of physically adsorbed water on the surface of particles. When the relative humidity increased to a critical value, the amount of absorbed water increased abruptly. This critical relative humidity was socalled deliquescence $\mathrm{RH}$. The DRHs were determined to be $75 \%, 79 \%$, and $81 \%$ for $\mathrm{NaCl}, \mathrm{NH}_{4} \mathrm{NO}_{3}$, and $\left(\mathrm{NH}_{4}\right)_{2} \mathrm{SO}_{4}$, respectively. The $\mathrm{DRH}$ of $\mathrm{NaCl}$ at $75 \%$ agreed well with the values reported in the literature when various techniques were used, e. g., $75 \%$ by H-TDMA, ${ }^{13,15,39} 74 \%-76 \%$ by EDB, ${ }^{17,18}$ $75 \pm 2 \%$ by infrared extinction spectroscopy, ${ }^{19,40} 75 \pm 1 \%$ by ATR-FTIR, ${ }^{20} 75 \pm 0.8 \%$ by ESEM,${ }^{26} 73 \%$ by $\mathrm{AFM},{ }^{27}$ and $75-80 \%$ by TEM. $^{28}$ All of these values are within the range reported here of $75 \pm 2 \% \mathrm{RH}$. For $\left(\mathrm{NH}_{4}\right)_{2} \mathrm{SO}_{4}$, the DRH was 


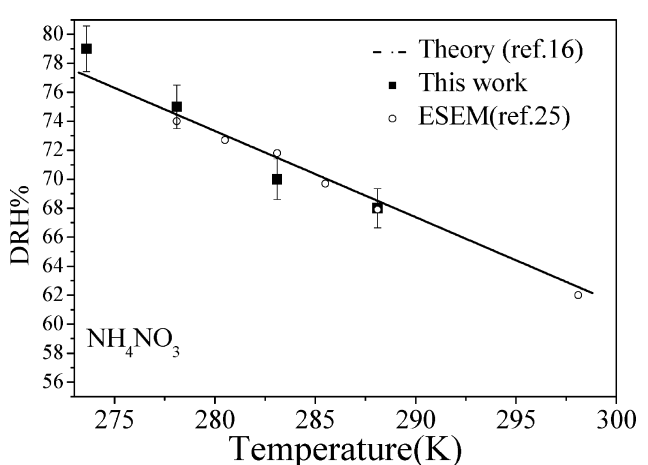

Figure 4. $\mathrm{DRH}$ of $\mathrm{NH}_{4} \mathrm{NO}_{3}$ as a function of temperature determined by a physisorption analyzer (solid square), compared with ESEM (empty circles, ref ${ }^{25}$ ), and calculated by eq 5 (dash line, ref 16). Error bars are $\pm 1 \%$ due to the deviation of temperature measurement.

$81 \%$, which was also found to be similar to those in the literature. The deliquescence of $\left(\mathrm{NH}_{4}\right)_{2} \mathrm{SO}_{4}$ was found to be 79 $\pm 1 \% \mathrm{RH}^{12}$ and $80 \pm 1 \% \mathrm{RH}^{8,39}$ by using H-TDMA, $79.9 \pm$ $0.5 \% \mathrm{RH}^{16}$ and $80.6-81.3 \% \mathrm{RH}^{17}$ using an EDB, $79 \pm 2 \%$ RH using a FT-IR flow system, ${ }^{19,20,40}$ and $81.3 \pm 1.5 \%$ RH using ESEM. ${ }^{25}$ All of these values are within the range reported here of $81 \pm 2 \% \mathrm{RH}$. These data suggest that the vapor adsorb instrument is suitable for measuring the hygroscopic behavior of soluble inorganic salts.

The DRH of $\mathrm{NH}_{4} \mathrm{NO}_{3}$ is $79 \%$ as shown in Figure 3. The value is different from other studies because the experiment temperatures were different, e.g., $61.8 \% \mathrm{RH}$ at $298 \mathrm{~K}$ by EDB and ${ }^{16}$ $64 \pm 1 \%$ at $298 \mathrm{~K}$ by ATR-FTIR. ${ }^{20}$ A theoretically calculated DRH value of $\mathrm{NH}_{4} \mathrm{NO}_{3}$ was reported to be at $62 \% \mathrm{RH}$ using a multicomponent thermodynamic model. ${ }^{41}$ The difference between our result and the values reported in literature was due to the different experimental temperature (273 and $298 \mathrm{~K}$ ). The temperature dependence of DRH was postulated by Tang and Munlkelwitz ${ }^{16}$ as

$$
\begin{aligned}
\operatorname{DRH}(T)=\operatorname{DRH}(298) \exp \left\{\frac { \Delta H _ { s } } { R } \left[A\left(\frac{1}{T}-\frac{1}{298}\right)-\right.\right. \\
\left.\left.B \ln \frac{T}{298}-C(T-298)\right]\right\}
\end{aligned}
$$

where $\operatorname{DRH}(T)$ is the deliquescence relative humidity at temperature $T$ (in kelvin), $\operatorname{DRH}(298)$ is the deliquescence relative humidity at $298 \mathrm{~K}, \Delta H_{\mathrm{s}}$ is the enthalpy of solution, $R$ is the gas constant, and $A, B$, and $C$ are empirical constants. For $\mathrm{NH}_{4} \mathrm{NO}_{3}$, the $\Delta H_{\mathrm{s}}, A, B$, and $C$ are $16.25 \mathrm{~kJ} / \mathrm{mol}, 4.298$, $-3.623 \times 10^{-2}$, and $7.853 \times 10^{-5}$, respectively. ${ }^{16}$ The temperature dependence of DRH of $\mathrm{NH}_{4} \mathrm{NO}_{3}$, as well as the results of
Ebert et al. ${ }^{25}$ by using ESEM and the theoretical prediction by Tang et al., ${ }^{16}$ is shown in Figure 4. Our result is in agreement with the ESEM results and the theoretical prediction. It was postulated that the temperature dependence of DRH was related to the temperature dependence solubility of the salt in solution. ${ }^{16}$ When the temperature increased from 273 to $298 \mathrm{~K}$, for $\mathrm{NaCl}$ and $\left(\mathrm{NH}_{4}\right)_{2} \mathrm{SO}_{4}$, the solubilities ${ }^{42}$ increased slightly from 35.8 and 70.3 to 36.0 and $76.3 \mathrm{~g} / 100 \mathrm{~g}$ of $\mathrm{H}_{2} \mathrm{O}$, respectively. Therefore, the DRH reported in different studies with different experimental temperatures exhibits little variety. However, for $\mathrm{NH}_{4} \mathrm{NO}_{3}$, the solubility at $298 \mathrm{~K}\left(212.5 \mathrm{~g} / 100 \mathrm{~g}\right.$ of $\left.\mathrm{H}_{2} \mathrm{O}\right)$ was nearly double to that at $273 \mathrm{~K}\left(117.4 \mathrm{~g} / 100 \mathrm{~g}\right.$ of $\left.\mathrm{H}_{2} \mathrm{O}\right)$, which led to a marked temperature dependence of DRH.

Growth Factors and Efflorescence. The growth factor (GF) of the aerosol particle is defined as the diameter of the particle at a relative humidity, $\mathrm{RH}(D)$, divided by the diameter of the dry particle (particle at $\mathrm{RH}=0, D_{0}$ ), and it can be expressed as

$$
\mathrm{GF}=\frac{D}{D_{0}}
$$

For completely soluble particles, the growth factors can be calculated as ${ }^{15}$

$$
\mathrm{GF}=\sqrt[3]{\frac{\rho_{\mathrm{d}}}{\rho_{\mathrm{sol}}}\left(1+\frac{1}{m M_{\mathrm{d}}}\right)}
$$

where $\rho_{\mathrm{d}}$ and $\rho_{\text {sol }}$ are the densities of the dry particle and the solution droplet, respectively, $m$ is the molality of the solution, and $M_{\mathrm{d}}$ is the molar weight of the dissolved material. The densities for dry $\mathrm{NaCl}$ and $\left(\mathrm{NH}_{4}\right)_{2} \mathrm{SO}_{4}$ particles at $298 \mathrm{~K}$ are 2.165 and $1.769 \mathrm{~g} / \mathrm{cm}^{3}$, respectively. ${ }^{44}$ These density values were used in this study because they are seldom changed from temperature 298 to $273 \mathrm{~K}$. The solution densities for $\mathrm{NaCl}$ and $\left(\mathrm{NH}_{4}\right)_{2} \mathrm{SO}_{4}$ water solutions were calculated using formulas tabulated by Hämeri et al. ${ }^{14,43}$ The growth factors for $\mathrm{NaCl}$ and $\left(\mathrm{NH}_{4}\right)_{2} \mathrm{SO}_{4}$ determined in this work, as well as by ESEM ${ }^{25}$ and TDMA, ${ }^{13-15,39}$ are compared in Figure 5. These calculated growth factors should be considered as average values in this way; however, the deviation between these different approaches is very small. The growth factors for $\mathrm{NaCl}$ and $\left(\mathrm{NH}_{4}\right)_{2} \mathrm{SO}_{4}$ at $90 \%$ RH are 2.3 and 1.7, respectively, which are the same values as that reported by TDMA studies. ${ }^{29}$ All measurements shown in Figure 5 were performed with grains large enough $(\geq 100$ $\mathrm{nm}$ diameter) where the Kelvin effect is negligible. ${ }^{45}$
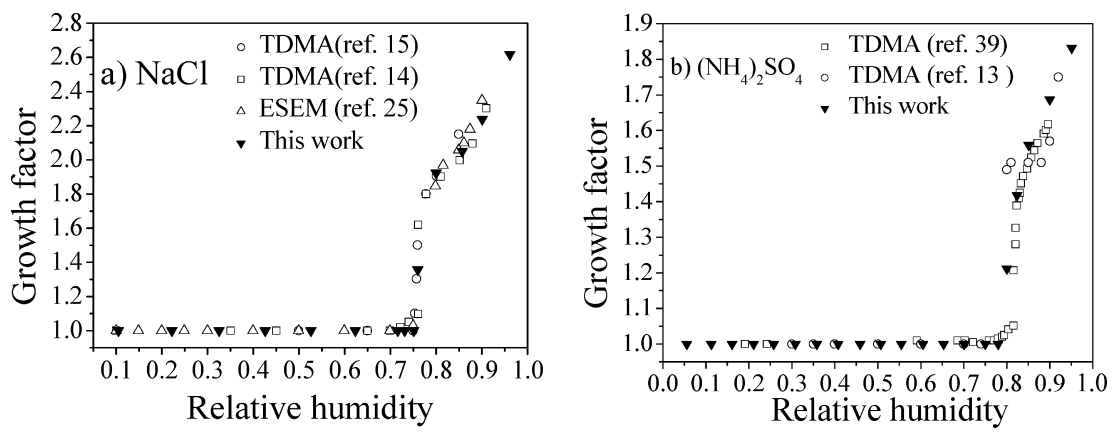

Figure 5. Growth factors of (a) $\mathrm{NaCl}$ and (b) $\left(\mathrm{NH}_{4}\right)_{2} \mathrm{SO}_{4}$ particles determined by physisorption analyzer (this work solid triangle) and by ESEM (empty triangle) and T-DMA (empty square and empty cycle). 


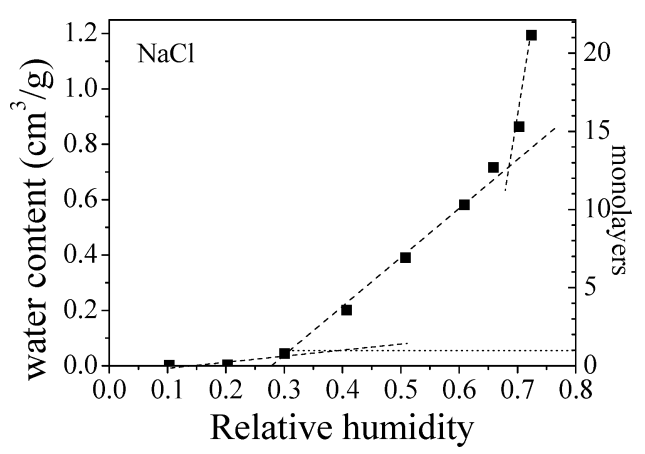

Figure 6. Adsorption isotherm of water on $\mathrm{NaCl}$ at low $\mathrm{RH}(0.1-0.72)$.

Efflorescence, the crystallization of the solid salt particles as $\mathrm{RH}$ decreases, can occur at a very different relative humidity because it is often a kinetically and not thermodynamically controlled process; therefore, the efflorescence relative humidity (ERH) typically occurs at lower relative humidity than DRH. For $\mathrm{NaCl}$, there is a clear hysteresis between desorption and adsorption isotherms, and the water content was constant below $55 \%$ RH (data not shown). It seems that the hydrated $\mathrm{NaCl}$ crystal $\left(\mathrm{NaCl} \cdot n \mathrm{H}_{2} \mathrm{O}\right)$ was formed. However, it is also reasonable to explain this phenomenon due to the interaction between solution and substrate (sample tube wall, glass). The substrate effect (heterogeneous nucleation occurred) on desorption of water was also observed in ESEM studies. ${ }^{25,26}$ Therefore, the accurate measurement of ERH was not available in this system.

RH for Monolayer Determined. The adsorption isotherm of water on $\mathrm{NaCl}$ at low relative humidity $(0.1-0.72)$ is shown in Figure 6. This experiment with the same accuracy as $\mathrm{N}_{2}$ adsorption experiments requires more time to achieve equilibrium, which therefore is only suitable for studying the predeliquescence process. Knowing the surface area of $\mathrm{NaCl}\left(A_{\mathrm{BET}}=\right.$ $\left.0.22 \mathrm{~m}^{2} / \mathrm{g}\right)$, the mass of water adsorbed was converted into coverage in terms of formal monolayers by making a reasonable assumption about the size of the adsorbed water molecules (14.3 $\left.\AA^{2}\right) .{ }^{21}$ On the basis of this assumption, we calculate that one monolayer is formed between 30 and $40 \% \mathrm{RH}$. It is also noted that there are three regions $(0-30 \%, 30-65 \%$, and $>65 \% \mathrm{RH})$ for water adsorption with different increase rates. The dissolution process of salts is complex. Hucher et al. ${ }^{46}$ have measured the electrical conductivity of the solution on a cleaved $\mathrm{NaCl}(001)$ face as a function of relative humidity, and three distinct regions of surface conductivity were found that describe the development of the water adlayer. The difference of conductivities was hypothetically due to different current carriers, i.e., $\mathrm{H}^{+}$ions for regions below $40 \% \mathrm{RH}$, solvated $\mathrm{Na}^{+}$ions for regions between $40 \%$ and $50 \% \mathrm{RH}$, and both $\mathrm{Cl}^{-}$and $\mathrm{Na}^{+}$ions for regions beyond $50 \%$ RH. AFM interrogation by Shindo et al. ${ }^{47}$ showed no step migration below $40 \% \mathrm{RH}$ but found movement gradually $\left(\sim 1 \mathrm{~nm} \mathrm{~min}{ }^{-1}\right)$ setting in at $47 \% \mathrm{RH}$ and precipitously ( $>10$ $\mathrm{nm} \mathrm{min}^{-1}$ ) near $65 \% \mathrm{RH}$. AFM study with a noncontact model by Dai et al. ${ }^{27}$ revealed that surface steps play a critical role on the water adsorption. It showed that a uniform layer of water was formed in which surface steps were evolved slowly above $\sim 35 \% \mathrm{RH}$ and water adsorbed primarily at the step edges at humidity levels less than $30 \%$. An AFM study by $\mathrm{Xu}$ and Salmeron ${ }^{48}$ suggested that at about $45 \%$ RH, which was lower than the DRH, a film that is several molecules thick begins to form which begins to hydrate ions at the surface. Our results showed that after the monolayer formed, the amount of water adsorbed increased markedly. As the coverage increases, there are more occurrences of ions incorporated into the water thin film as solvation becomes possible. The solvated ions reduced the saturated pressure of water which led the further adsorption of water. With the vapor pressure approaching its deliquescence value, the liquid layer resembles saturated solution.

From a molecular level of view, a water molecule colliding with a surface which is not yet completely covered by water may adsorb at a (reactive) surface site and/or may desorb into the gas phase. If the density of the reactive surface sites is high enough, a monolayer will readily form and the particle is completely covered with water. Consequently the particle is activated for water condensation and may be regarded as hydrophilic. Thus, adsorption and desorption rates together with the amount of water adsorbed represent important parameters in the assessment of the hydrophilicity of an atmospheric particle. ${ }^{49}$ Our results also support this point that the particle was activated when the monolayer thin film water was formed at the surface, as shown in Figure 6. The water adsorbed amount was about 4 factors higher than that reported by Forster and Ewing, ${ }^{22}$ when the thin film water adsorbed on single crystal $\mathrm{NaCl}$ (001) was studied by infrared spectroscopy. Since the polycrystalline bulk material was used in this study, the water molecules aggregate into islands at low coverages ${ }^{22}$ more than on single crystals. Moreover, as mentioned above, infrared spectroscopic methods always make a relative underestimated quantitative result because of its saturated effect. Therefore, it is not hard to understand the discrepancy about the amount of water adsorbed.

\section{Conclusions}

This technique provides a new method to test the water adsorption capacity of soluble and insoluble but wettable aerosol particles. Qualitative and quantitative information related to uptake of water by atmospherically relevant particles, such as deliquescence relative humidity, growth factors, and monolayer relative humidity, were obtained. $\mathrm{DRH}$ for $\mathrm{NaCl}(75 \%)$, $\left(\mathrm{NH}_{4}\right)_{2} \mathrm{SO}_{4}(81 \%)$, and $\mathrm{NH}_{4} \mathrm{NO}_{3}(79 \%)$ and the temperature dependence of the DRH of $\mathrm{NH}_{4} \mathrm{NO}_{3}$ can be measured with an uncertainty less than $2 \%$. Growth factors were calculated for $\mathrm{NaCl}$ and $\left(\mathrm{NH}_{4}\right)_{2} \mathrm{SO}_{4}$ which are 2.3 and 1.7 at $90 \% \mathrm{RH}$, respectively. For $\mathrm{NaCl}$, the predeliquescence process below the DRH exhibits three stages $(0-30 \%, 30-65 \%$, and $>65 \% \mathrm{RH})$ where water adsorption amount increase rates are different. Water adsorption isotherms for $\mathrm{Al}_{2} \mathrm{O}_{3}$, as a representation of insoluble aerosol particles, could be measured with this instrument. The versatility of this instrument makes it suitable for studying the hygroscopic behavior of most atmospheric particles, which always contains both soluble and insoluble compounds. It could improve our understanding about the hygroscopic behavior of atmospheric particles.

Acknowledgment. This work was funded by National Natural Science Foundation of China (20877084, 20937004), the Chinese Academy of Sciences (KZCX2-YW-Q02-03), and the Ministry of Science and Technology, China (2007CB407301).

\section{References and Notes}

(1) http://en.wikipedia.org/wiki/Aerosol.

(2) Pandis, S. N.; Wexler, A. S.; Seinfeld, J. H. J. Phys. Chem. 1995, 99 (24), 9646-9659.

(3) Intergovernmental Panel on Climate Change (IPCC) (2007), Summary for policymakers. In Climate Change 2007: The Physical Science Basis. Contribution of Working Group I to the Fourth Assessment Report of the Intergovernmental Panel on Climate Change; Solomon, S., et al., Eds.; Cambridge University Press: New York, 2007; pp 1-18.

(4) Ramanathan, V.; Crutzen, P. J.; Kiehl, J. T.; Rosenfeld, D. Science 2001, 294, 2119-2124. 
(5) Pilinis, C.; Pandis, S. N.; Seinfeld, J. H. J. Geophys. Res. 1995, 100 (D9), 18739-18754.

(6) Pruppacher, H. R.; Klett, J. D. Microphysics of Clouds and Precipitation; Kluwer Academic: Norwell, MA, 1997.

(7) Charlson, R. J.; Schwartz, S. E.; Hales, J. M.; Cess, R. D.; Coakley,

J. A., Jr.; Hansen, J. E.; Hofmann, D. J. Science 1992, 255, 423-430.

(8) Gibson, E. R.; Hudson, P. K.; Grassian, V. H. J. Phys. Chem. A 2006, 110 (42), 11785-11799.

(9) Cwiertny, D. M.; Young, M. A.; Grassian, V. H. Annu. Rev. Phys. Chem. 2008, 59, 27-51.

(10) Orr, C., Jr.; Hurd, F. K.; Hendrix, W. P.; Junge, C. J. Meteorol. 1958, 15, 240-242.

(11) Rader, D. J.; McMurry, P. H. J. Aerosol Sci. 1986, 17 (5), 771787.

(12) Weingartner, E.; Gysel, M.; Baltensperger, U. Environ. Sci. Technol. 2002, 36 (1), 55-62.

(13) Cruz, C. N.; Pandis, S. N. Environ. Sci. Technol. 2000, 34 (20), 4313-4319.

(14) Hämeri, K.; Laaksonen, A.; Väkevä, M.; Suni, T. J. Geophy. Res. 2001, 106 (D18), 20749-20757.

(15) Joutsensaari, J.; Vaattovaara, P.; Vesterinen, M.; Hämeri, K.; Laaksonen, A. Atmos. Chem. Phys. 2001, 1, 51-60.

(16) Tang, I. N.; Munkelwitz, H. R. Atmos. Environ. 1993, 27 A (4), 467-473.

(17) Cohen, M. D.; Flagan, R. C.; Seinfeld, J. H. J. Phys. Chem. 1987, 91 (17), 4563-4574.

(18) Chan, C. K.; Ha, Z.; Choi, M. Y. Atmos. Environ. 2000, 34, 47954803.

(19) Cziczo, D. J.; Abbatt, J. P. D. J. Phys. Chem. A 2000, 104 (10), 2038-2047.

(20) Schuttlefield, J.; Al-Hosney, H.; Zachariah, A.; Grassian, V. H. Appl. Spectrosc. 2007, 61, 283-292.

(21) Gustafsson, R. J.; Orlov, A.; Badger, C. L.; Griffiths, P. T.; Cox, R. A.; Lambert, R. M. Atmos. Chem. Phys. 2005, 5, 3415-3421.

(22) Foster, M. C.; Ewing, G. E. J. Chem. Phys. 2000, 112 (15), 68176826.

(23) Zhang, Y. H.; Chan, C. K. J. Phys. Chem. A 2002, 106 (2), 285292.

(24) Liu, Y. J.; Zhu, T.; Zhao, D. F.; Zhang, Z. F. Atmos. Chem. Phys. 2008, 8, 7205-7215.

(25) Ebert, M.; Inerle-Hof, M.; Weinbruch, S. Atmos. Environ. 2002, $36,5909-5916$.

(26) Krueger, B. J.; Grassian, V. H.; Iedema, M. J.; Cowin, J. P.; Laskin, A. Anal. Chem. 2003, 75 (19), 5170-5179.

(27) Dai, Q.; Hu, J.; Salmeron, M. J. Phys. Chem. B 1997, 101 (1), 1994-1998.
(28) Wise, M. E.; Biskos, G.; Martin, S. T.; Russell, L. M.; Buseck, P. R. Aerosol Sci. Technol. 2005, 39, 849-856.

(29) Swietlicki, E.; Hansson, H.-C.; Hämeri, K.; Svenningsson, B.; Massling, A.; Mcfiggans, G.; McMurry, P. H.; Petäjä, T.; Tunved, P.; Gysel, M.; Topping, D.; Weingartner, E.; Baltensperger, U.; Rissler, J.; Wiedensohler, A.; Kulmala, M. Tellus 2008, 60B, 432-469.

(30) Goodman, A. L.; Bernard, E. T.; Grassian, V. H. J. Phys. Chem. A 2001, 105 (26), 6443-6457.

(31) Sing, K. S. W.; Everett, D. H.; Haul, R. A. W.; Moscou, L.; Pierotti, R. A.; Rouquérol, J.; Siemieniewska, T. Pure Appl. Chem. 1985, 57 (4), 603-609.

(32) Goudie, A. S.; Middleton, N. J. Earth-Sci. Rev. 2001, 56, 179204.

(33) Zhang, X. Y.; Gong, S. L.; Shen, Z. X.; Mei, F. M.; Xi, X. X.; Liu, L. C.; Zhou, Z. J.; Wang, D.; Wang, Y. Q.; Cheng, Y. J. Geophy. Res. 2003, 108 (D9), 4261.

(34) Brunauer, S.; Emmett, P. H.; Teller, E. J. Am. Chem. Soc. 1938, $60,309-319$.

(35) Brunauer, S.; Skalny, J.; Bodor, E. E. J. Colloid Interface Sci. 1969, 30 (4), 546-552.

(36) Tóth, J. Adsorption: Theory, Modeling, and Analysis; Marcel Dekker: New York, 2001.

(37) Joyner, L. G.; Weinberger, E. B.; Montgomery, C. W. J. Am. Chem. Soc. 1945, 67, 2182-2188.

(38) Morishige, K.; Harada, K. Langmuir 2001, 17, 7291-7295.

(39) Gysel, M.; Weingartner, E.; Baltensperger, U. Environ. Sci. Technol. 2002, 36 (1), 63-68.

(40) Cziczo, D. J.; Nowak, J. B.; Hu, J. H.; Abbatt, J. P. D. J. Geophys. Res. 1997, 102 (D15), 18843-18850.

(41) Clegg, S. L.; Brimblecombe, P.; Wexler, A. S. J. Phys. Chem. A 1998, 102 (12), 2155-2171.

(42) Solubility Data Series; International Union of Pure and Applied Chemistry; Pergamon Press: Oxford, 1995.

(43) Hämeri, K.; Väkevä, M.; Hansson, H.-C.; Laaksonen, A. J. Geophys. Res. 2000, 105 (D17), 2223122242.

(44) www.en.wikipedia.org.

(45) Kreidenweis, S. M.; Koehler, K.; DeMott, P.; Prenni, A. J.; Carrico, C.; Ervens, B. Atmos. Chem. Phys. 2005, 5, 1357-1370.

(46) Hucher, M.; Oberlin, A.; Hocart, R. Bull. Soc. Fr. Mineral. Cristallogr. 1967, 90, 320.

(47) Shindo, H.; Ohashi, M.; Baba, K.; Seo, A. Surf. Sci. 1996, 357358, 111-114.

(48) Xu, L.; Bluhm, H.; Salmeron, M. Surf. Sci. 1998, 407, 251-255.

(49) Seisel, S.; Pashkova, A.; Yu, L.; Zellner, R. Faraday Discuss. 2005, 130, 437-451.

JP909340V 